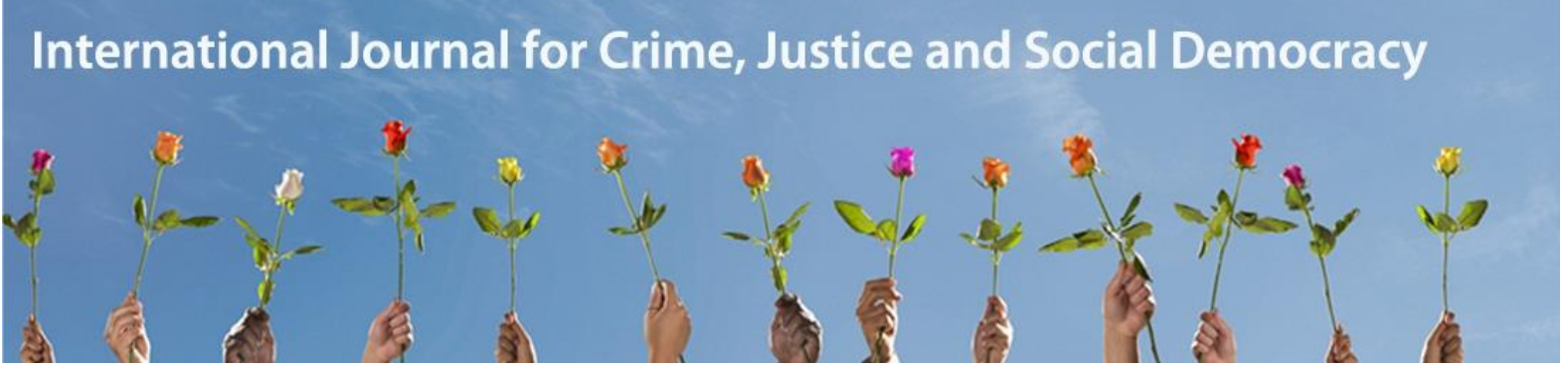

\title{
Putting 'Justice' in Recovery Capital: Yarning About Hopes and Futures with Young People in Detention
}

\author{
Sharynne L. Hamilton \\ Telethon Kids Institute, Perth, Australia \\ Sarah Maslen \\ University of Canberra, Australia \\ David Best \\ University of Derby, United Kingdom \\ Jacinta Freeman \\ Telethon Kids Institute, Australia \\ Melissa 0'Donnell \\ Telethon Kids Institute, Australia \\ Tracy Reibel \\ Murdoch University, Australia \\ Raewyn C. Mutch \\ Telethon Kids Institute, Australia \\ Rochelle Watkins \\ Telethon Kids Institute, Australia
}

\begin{abstract}
Aboriginal and Torres Strait Islander young people are over-represented in Australian youth detention centres and the justice system. In contrast to deficit-focused approaches to health and justice research, this article engages with the hopes, relationships and educational experiences of 38 detained youth in Western Australia who participated in a study of screening and diagnosis for fetal alcohol spectrum disorder. We report on a qualitative study that used a 'social yarning' approach. While the participants reported lives marred by substance use, crime, trauma and neurodevelopmental disability, they also spoke of strong connections to country and community, their education experiences and their future goals. In line with new efforts for a 'positive youth justice' and extending on models of recovery capital, we argue that we must celebrate success and hope through a process of mapping and building recovery capital in the justice context at an individual and institutional level.
\end{abstract}

\section{Keywords}

Youth Justice; Recovery Capital; Indigenous; Aboriginal; FASD; neurodevelopmental disability; hope.

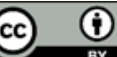

This work is licensed under a Creative Commons Attribution 4.0 International Licence. As an open access journal, articles are free to use with proper attribution. ISSN: 2202-8005 


\section{Introduction}

Globally, Indigenous peoples are over-incarcerated (Reitano 2017; Ulmer and Bradley 2018). Australia is no exception, with Indigenous peoples comprising 27 per cent of the prison population, which is 13 times the rate of non-Indigenous prisoners (Australian Bureau of Statistics 2017). Incarcerated Indigenous youth comprise 59 per cent of all youth in detention, despite only making up five per cent of the population (Australian Institute of Health and Welfare 2018). In Western Australia (WA), where this research was undertaken, Indigenous youth make up 70 per cent of youth in detention (Office of the Inspector of Custodial Services 2018).

Various key factors explain the over-representation of incarcerated Indigenous people in settlercolonial countries, including the shift away from traditional life (Bougie and Senecal 2010; Kaspar 2014; MacDonald and Steenbeek 2015) and systemic and institutional racism and discrimination (Blagg 2008; Harmes, Hopkins and Farley 2019; Weatherburn and Ramsey 2016). In Australia, the fabric of Aboriginal and Torres Strait law and society was disrupted by the intrusion of white settlers, and colonisation was advanced by policies and practices such as the forced removal of children from their parents, families and communities; compulsory land relinquishment and restricted freedoms through incarceration (De Maio et al. 2005; Memmott et al. 2001). This resulted in a pattern of over-incarceration, which is a situation that increases the likelihood that trauma and colonisation are continued (Blagg 2008; Rynne and Cassematis 2015).

It must be acknowledged that, generally, justice-involved youth are traumatised populations with high levels of mental health problems, conduct disorders, self-harm, and alcohol and other drug (AOD) use (Indig, Frewen and Moore 2016). The nexus between criminality, mental health problems, AOD problems and crime trajectories is well established internationally (Bennett and Holloway 2009; Caudy, Tillyer and Tillyer 2018; Hafekost et al. 2017; Indig, Frewen and Moore 2016). This is compounded among Indigenous youth, who have higher levels of neurocognitive disability (Baldry et al. 2015; Dias et al. 2013), intellectual disability (Indig et al. 2011) and fetal alcohol spectrum disorder (FASD) (Blagg, Tulich and Bush 2015; Bower et al. 2018) compared with their non-Indigenous peers.

In this article, we report the qualitative findings of a first-of-its-kind Australian study that was undertaken to establish the prevalence of FASD among youth sentenced to detention in Banksia Hill Detention Centre (Banksia) in WA between 2015 and 2017 (Bower et al. 2018; Passmore et al. 2016; Passmore et al. 2018; Freeman et al. 2018; Kippin et al. 2018; Hamilton et al. 2019a; Hamilton et al. 2019b). The article focuses on specific facets of participants' recovery capital: happiness and hopes for the future, family relationships, and networks and connections.

FASD, which is a lifelong condition, describes a range of anomalies in brain function caused by maternal alcohol consumption during pregnancy. Individuals with FASD have difficulty with memory, attention, judgement and impulse control (Fast and Conry 2004) and many have communication and language impairments (Snow, Bagley and White 2017; Kippin et al. 2018).

FASD limits an individual's understanding of social expectations (Fast and Conry 2004) and results in learning difficulties, poor school performance and reduced prospects for employment (McLachlan et al. 2014). Internationally, FASD is significantly correlated with criminal justice involvement and the number of individuals with FASD is disproportionate to the total number of justice-involved people (Fast and Conry 2004; Streissguth and O’Malley 2000).

Individuals with FASD who come into contact with the justice system raise serious concerns about fairness and equity. When they come into contact with police, they may experience an impaired understanding of why they are in trouble and have a poor understanding or comprehension of their arrest rights (Roach and Bailey 2009). They can be highly suggestible, have poor concepts of time and sequence, and have sporadic memory recall (Fast and Conry 2004). They are more 
likely to succumb to pressure to plead guilty without an understanding of legal or personal consequences (McLachlan et al. 2014). Finally, they may struggle to understand the effect of their behaviour, potentially leaving them vulnerable to being viewed as lacking remorse or compassion (Roach and Bailey 2009). Knowing the prevalence and understanding the effects of FASD in youth justice systems is imperative.

Internationally, youth justice systems ascribe to many narratives: 'child protection', 'punishment', 'public interest', 'public safety', 'welfare' and 'rights' (Goldson and Muncie 2012). 'Punitive justice' models, which give precedence to proportionate punishment, formal sentencing and administration of accountability (Morris and Giller 1983), and 'correctionalism' models, which seek to control and correct an individual's flaws and weaknesses (Farrington 2007), are dominant. These models assume children and young people make rational choices, offend with 'free will' and therefore require discipline, control and accountability for their actions. In their discussion on Indigenous youth with FASD in WA, Blagg, Tulich and Bush (2015) highlighted that Western criminal justice systems, and in particular their diversion practices, do not realistically consider that youth with FASD do not 'mature' out of crime or respond to desistance from offending, lessened police interaction or access to desired stability or productivity.

Given Australia's colonial history and the resulting challenges that bring youth into contact with the law, there is a need to explore relational frameworks (Slade 2010; Burford, Braithwaite and Braithwaite 2019) that privilege the voices and knowledges of these youth and consider the broader aspects of their lives. Positive youth justice (PYJ) is an approach that argues against the punitive youth justice policies and practices that dominate Western approaches to crime (Cavadino and Dignan 2006; Cunneen and Rowe 2014; Dunkel 2014; Goddard and Myers 2017; Winterdyck 2014). Rather than prioritising the prevention of youth crime, the focus of PYJ is on developing six key areas for youth: health, work, education, communities, creative skillsets, and social networks and relationships (Butts, Bazemore and Meroe 2010).

Consistent with these PYJ principles, this article investigates the potential for a 'recovery capital' lens to shift focus to the importance of relationships and networks for justice-involved young people's recovery and healing. Although this introduction has focused on Indigenous youth and the effects of colonisation, the authors consider a recovery capital approach to be beneficial for all youth involved in the criminal justice system. After outlining recovery capital approaches, we present the study findings and explore how recovery capital can benefit these justice-involved youth.

\section{Applying Recovery Capital Approaches to Justice-Involved Youth}

Recovery capital was originally developed in the context of recovery from severe AOD problems (Granfield and Cloud 2001). It is a dynamic and interactive strength-based model that attempts to measure the range of internal and external resources that can be used to initiate and sustain recovery (Cloud and Granfield 2009). Recovery capital has also been applied in the broader context of recovery from mental health issues and trauma, which are adversities that often encompass the lives of justice-involved youth (Hafekost et al. 2017; Indig, Frewen and Moore 2016).

Recovery is conceptualised at three levels: personal, social and community (Best and Laudet 2010). Personal recovery capital represents an individual's level of personal skills, abilities and personal resources including self-esteem, self-efficacy, coping mechanisms and resilience (Cloud and Granfield 2009; Best and Laudet 2010). It includes individual communication skills, interpersonal and educational/vocational skills, problem-solving capacities, hope, optimism and goals. 
Social recovery capital refers to the recovery supports available to individuals (Cloud and Granfield 2009; Best and Laudet 2010). The concept of social capital was initially developed by Bourdieu (1985) and scholars have argued the importance of social capital and networks for providing a sense of belonging (Durkheim 1984) and as a resource rich in trust, mutual obligation and reciprocity (Putnam 2000). In the context of recovery capital, social capital allows for identification of intimate relationships, family networks and broader social relationships, and constitutes the availability of culturally prescribed pathways that resonate with particular individuals and families, including models for Indigenous peoples (Coyhis and White 2006). It supports analysis of the willingness and capacity of family members to participate in treatment, access to prosocial activities, and interpersonal connections to others in institutions such as school, work and community organisations.

Community recovery capital refers to the tangible influences on recovery such as having access to safe housing and meaningful opportunities (Brunelle, Cousineau and Brochu 2005; White and Cloud 2008). This can be built up through the promotion of community attitudes; policies and resources that support the resolution of problems; active community efforts to reduce stigma associated with addiction and recovery; increased visibility and diversity of peers and positive role models; comprehensive resource provision; and increased local recovery community support institutions (Brunelle, Cousineau and Brochu 2005). Resources can include specific recovery rehabilitation centres, playgroups, schools, healing initiatives, parenting centres, peerled self-help groups and sporting clubs (White and Cloud 2008; Best 2014).

Within a recovery capital model, recovery is viewed as a staged process that involves destabilising a problem, initiating recovery and stability, and then maintaining recovery (Laudet, Morgen and White 2006; White and Cloud 2008) while acknowledging that individuals possess different aspects of recovery capital that can change over time. However, aspects of recovery capital interact with the severity or complexity of problems, which in turn shape the intensity of the support and the length of time for which support may be needed (Laudet, Morgen and White 2006). The process of destabilising a problem and initiating recovery possibilities can occur within institutions, whether they be hospitals, rehabilitation centres, psychiatric facilities or prisons (Laudet, Morgen and White 2006; White and Cloud 2008; Best 2014; Best 2019).

Many obstacles can stand in the way of recovery, which is a problem that creates what Cloud and Granfield (2009) refer to as 'negative recovery capital'. Justice-involved individuals, particularly those with additional problems such as addiction, can be negatively labelled (Dingle et al. 2014), experience stigma and marginalisation (Scott and Gosling 2016) and thus be excluded from various forms of social and community capital. Moreover, some groups in communities do not have a positive effect on physical or psychological wellbeing, or the recovery process (Haslam et al. 2012; Jetten et al. 2014; Best and Savic 2015). Belonging to such groups sustains negative values and lifestyles and presents barriers to accessing and utilising resources in the community such as education, jobs and safe housing (Best and Savic 2015). Therefore, professional interventions need to provide opportunities to build positive social networks, enable access to community resources and reduce the potential for stigma (McNeill and Maruna 2007; McNeill and Whyte 2007; Ward and Maruna 2007; Best 2019).

Generally, the recovery capital approach has been targeted towards adult populations. Little is known about the benefits of establishing and building on the recovery capital assets possessed by youth (Hennessy 2017), and the authors found no literature that explored recovery capital models inclusive of Australian justice-involved youth or Australian Indigenous youth. The literature predominantly examines the role of peers in recovery from addiction; however, there are some related concepts that have been developed in the context of adolescents that point to the potential relevance of recovery capital approaches to these social groups. The peer recovery support model, which is closely related to Native American peoples' traditional kinship systems 
and values, has shown improvement in housing stability, employment and health for Native American peoples (Kelley et al. 2017). According to Nash and colleagues (2017), alternative peer group models have also received attention for youth in recovery, the authors positing that building networks and new friendships can provide different influences, attitudes, values, ideas and ways of doing things that support recovery. Highlighting that there are many gaps in recovery capital for specific populations, Hennessy (2017) identified that some aspects of recovery capital may further marginalise youth and argued for the need to understand youth's perceptions of what forms of community participation would lead to a healthy and meaningful life.

A recovery capital model constitutes a framework to assess recovery while being cognisant of the AOD use and mental health problems that are well established in the justice-involved youth population in Australia. However, for the case that we address in this article, the recovery capital model does not systematically consider how assessments for recovery capital assets can be applied to justice-involved youth with neurodevelopmental disability. For its success, many of the features of developing recovery capital rely on individuals having the ability to focus, communicate and initiate and maintain positive relationships. For justice-involved youth with neurodevelopmental disability, an enhancement of the recovery capital model is necessary to support effective communication and equitable participation in decision-making about their futures.

\section{Methods}

The findings reported here are part of a broader program of work that sought to assess the prevalence of FASD among detained youth in WA (Bower et al. 2018). A qualitative study was designed to gain an understanding of the participants' perspectives of FASD assessment. To gather this data, the researchers adopted the yarning method (Bessarab and Ng'andu 2010; Fredericks et al. 2011; Martin 2008). The essence of a yarn is listening and exchanging, with each side being willing to give information and show genuine connection to, empathy with and interest in the other, drawing on longstanding cultural practices used by Indigenous families and communities. In this research interaction, the researcher is an 'active participant' and 'learner' as opposed to the 'possessor of knowledge'. Yarning can be approached in four ways: social yarning, research topic yarning, collaborative yarning and therapeutic yarning (Bessarab and Ng'andu 2010). Our study used both social and research topic yarning. A yarning methods paper reporting research topic data for this study is published elsewhere (Hamilton et al. 2019b). As the lead researcher (first author) was an Aboriginal woman from the eastern states of Australia, yarning involved sharing information about traditional heritage and country, which is essential to honest and identifiable engagement in yarning (Bessarab and Ng'andu 2010). The participants exchanged information with the researcher about their family, where they lived, their school experiences and their hopes for the future. The data we report on in this article are drawn from the social yarning.

\section{Participants}

Purposive sampling was used to identify qualitative study participants from the 99 young people who completed the assessments in the prevalence study. Of these participants, 38 agreed to participate in a yarning interview. They self-identified their ethnicity; 27 identified as Aboriginal and 11 as non-Aboriginal Australian. No Torres Strait Islander youth participated in this study. The participants will be referred to as Aboriginal or non-Aboriginal participants.

At the time of the yarning interviews, the researcher had no knowledge of the participants' diagnostic outcomes. Subsequent analysis of the qualitative study found that 24 per cent of the participants had FASD and 34 per cent were diagnosed with neurodevelopmental impairments (NI) in the severe range. The remaining 42 per cent of the participants had not received a 
diagnosis; however, 89 per cent of the prevalence study participants were found to have at least one severe NI, making yarning appropriate to their interviewing needs (Hamilton et al. 2019b).

\section{Data Collection}

All but two interviews took place outdoors at Banksia and all yarns were in sight, but not in hearing, of custodial officers. The length of time of the yarns was between 10 and 30 minutes. A voice-recording device was not used during yarning. So as not to interfere with the yarning process, brief handwritten notes were taken during the interview, with salient points recorded in writing (verbatim) and accuracy double checked with the participants at the time of the interview. Immediately following the yarn, the researcher comprehensively documented the details of the interview in writing, including multiple reflective fieldnotes.

\section{Research Ethics}

Ethics approval for both the study was granted by the Western Australian Aboriginal Health Ethics Committee (approval number 582) and the University of Western Australia Human Research Ethics Committee (approval number RA/4/1/7116). Research approvals were also gained from the (former) Department of Corrective Services (project ID 335) and the (former) Department for Child Protection and Family Support (approval number 2015/8981).

\section{Informed Consent}

Assent from the young person and consent from their guardian to participate in the study was obtained by a research officer. Due to the vulnerability of this population, a child-centred approach to seeking assent was followed (Clark 2011). If a young person expressed interest in being involved in the study, the research officer explained the purpose of the study using simple language and pictorial information sheets and assent forms (Passmore et al. 2016). Upon assent, written consent was then sought from the participant's identified legal guardian. This approach to assent and consent recognised the capacity of young participants to be involved in informed decision-making about research participation while respecting the responsibility of their parents as their guardians to provide informed consent (Lambert and Glacken 2011).

\section{Data Analysis}

Data were analysed using thematic analysis (Attride-Stirling 2001). We used the methods of interpretive phenomenological analysis (Smith, Flower and Larkin 2009) to interpret the interview data. Study team members met regularly and reviewed the themes in the data that had been noted by the lead researcher. These reviews helped to ensure consistency in data interpretation over the time of data analysis using diverse perspectives and many iterations. Initially, two researchers manually analysed and coded the data using NVivo Pro Qualitative Data Analysis Software (2016). The lead researcher also conducted multiple analysis reviews over time to confirm and develop final data interpretations. The authors then cross-analysed the data for these aspects of recovery capital.

\section{Results}

The following analysis examines the participants' yarns through the lens of the recovery capital model (i.e., personal, social and community recovery). Diagnosis is indicated for FASD [FASD], neurodevelopmental impairments [NI] and participants without diagnosis [WD]. Most of the young people experienced a confluence of difficulties, such as previously identified mental health and conduct disorders and AOD use (Bower et al. 2018). 


\section{Personal Recovery Capital: Happiness and Hope}

Overwhelmingly, participants with and without a diagnosis found happiness within their family relationships. When asked by the researcher 'what makes you happy?', responses from the nonAboriginal participants included 'being home with my family makes me happy' and 'I'm happy when I have had a visit with Mum'. The Aboriginal participants also spoke of cultural activity: 'I'm happy being with family, like getting out on country like and learning about medicines and catching bush meat'; 'I'm really happy when I go hunting goanna and turtle with my dad'; and 'I like fishing with Pop'. Four of the participants, two Aboriginal and two non-Aboriginal, had their own children and expressed that their children provided hope, purpose and happiness. One participant said, 'I can't wait to get out so I can spend some time with my little daughter'.

\section{Personal Recovery Capital: Futures}

Many participants yarned about going back to school or taking up trades on their release, particularly those from the urban region. They identified many occupations in which they would like the opportunity to work, including as a plumber, electrician, mechanic, welder, bricklayer and carpenter or builder.

One non-Aboriginal participant [FASD] said, 'I want to do bricklaying or work in construction'. A non-Aboriginal participant [NI] yarned about wanting 'to be an electrician'.

A non-Aboriginal participant [WD] saw opportunities to pursue these aspirations through Banksia: 'I'm doing a construction certificate here [at Banksia]. It's good cause I never got opportunities to succeed and I want to do cabinet making and get a carpentry certificate'. While in Banksia, this participant was proud that they had made 'little wooden things' for their child.

Most of the Aboriginal participants from remote and regional WA wanted to join an Indigenous rangers program, be a station hand or wanted to be involved at some level in community programs and looking after country. One participant [WD] said, 'I hope to I can go back and live with Mum and Dad and I want to work on my country with the Indigenous Rangers'.

Another participant [NI] said, 'I want to go and work on a station. I love animals and can't wait to go home'. Other Aboriginal participants, all from remote or regional communities, said: [WD]: 'I am hoping to go to an alternative type of schooling. I would like to see a bush school for the young people in my [remote] community'; [FASD]: 'I want to get a [drivers] licence and work on the mines or on a station'; [FASD]: 'I want to be a [Indigenous] ranger and look after the country'.

Some of the participants wanted more professional futures. One non-Aboriginal participant [WD] wanted to undertake a business course and run their own business, while others wanted to work with computers or in accountancy, graphic design or music. One non-Aboriginal participant [NI] wanted to join the navy. Another non-Aboriginal participant [WD] said, 'I would like to be a custodial officer so then I could help kids like me'.

Some of the participants were more interested in having somewhere to live, a relationship and a family of their own. A non-Aboriginal participant [WD] said, 'I dream of having a big house on the beach with lots of kids and stability'. The participant went on to say, 'and I really want to travel'.

For a few participants, their goal was just to stay out of trouble and out of Banksia. One nonAboriginal participant [FASD] said, 'I just hope I don't have to come back [to Banksia]'. Another Aboriginal participant [FASD] said: 
I just want to stay off the drugs and keep out of trouble. If I have cravings [for drugs] I will do sport. I plan to do bricklaying. I know where to get help to do bricklaying, but the community doesn't understand why I get into trouble [alluding to FASD].

While almost all the participants spoke of their hopes and dreams for their futures, a minority were unable to identify positive futures. One non-Aboriginal participant [WD] identified smoking cannabis as their 'future career aspiration'. Two participants [one FASD one NI] saw their futures as bleak and did not know what they wanted to do. One Aboriginal participant [NI] envisioned his future as being 'in the big house across the road [pointing to the adult prison]'. An Aboriginal participant [FASD] said, 'there is nothing to hope for, I'm just going to smoke dope every day'. Finally, a non-Aboriginal participant [NI] said, 'I have no plans for when I leave Banksia. I'm not sure I can get a job anyway cause I'm a criminal'.

\section{Social Recovery Capital: Relationships and Networks}

As noted earlier in these results, most participants described happiness as being embedded in family relationships. While family relationships were a source of identity, happiness and cultural connection, there were complicating factors that could impede the potential for recovery. A few participants talked about their parents' use of drugs and identified family members as initiating their drug use.

One non-Aboriginal participant [WD] said, 'I love my mum and dad, but they use all kinds of drugs'. Another Aboriginal participant [FASD] said, 'I smoked cigarettes and drink alcohol with my family since I was 14' and another Aboriginal participant [NI] said: 'me and my bro [brother] use meth'. One Aboriginal participant [WD] recognised that their family's AOD use made it difficult for them to deal with their own AOD problem: 'I smoke and drink with my family, they all do it, so I do too ... it's pretty hard, you know'.

Many participants also spoke of other family members who were incarcerated, particularly male relatives. One Aboriginal participant [FASD] said, 'I don't know my dad 'cause he's been in the big house [adult prison] forever', while another Aboriginal participant [NI] said, 'My dad and brother are inside'. An Aboriginal participant [FASD] said, 'both my uncles were there [pointing across the road to the adult prison] but one of them hung himself'.

While the common experience of incarceration is devastating for communities, it can also be a source of support while in detention. An Aboriginal participant [WD] said, 'I'm ok, I'm in here with my cousins and nephews, and uncles'. This could extend to friendship networks, with a nonAboriginal participant [NI] commenting: 'I'm happy being here at Banksia ... because I feel safe and have friends here'.

Around a quarter of the participants had been in state child protection care prior to being incarcerated. These participants particularly yarned about instability. A non-Aboriginal participant [WD] said, 'I have lost count of how many foster homes I have lived in'. Another nonAboriginal participant [WD] spoke of losing touch with family: 'I haven't seen my parents for a few years now'. Another non-Aboriginal participant [WD] yarned about being repeatedly removed from and reunified with their mother and said, 'I went home a lot, but it never worked out'. Another Aboriginal participant [NI] said, 'I been away from my family for half my life; I get sad and angry'. This participant echoed the experiences of the other participants when they said, 'Miss, I just grew myself up'.

\section{Community Recovery Capital: Access to Education Opportunities}

Participants yarned about school experiences. Some participants liked school and described achievement. One non-Aboriginal participant [WD] was a 'gifted' student prior to their 
incarceration, while another non-Aboriginal participant had successfully completed school and an apprenticeship. Two Aboriginal participants had attended school on football scholarships. One of these participants went to school interstate but discontinued to return home. He said, 'I liked it [school], but I missed being with my mob [family]'. Many of the participants liked the social aspects of school, particularly sport. An Aboriginal participant [FASD] said, 'I like hangin with my bruz [brothers] but not the work; it's too hard'. Another Aboriginal participant [WD] said that the 'best part [of school] is playing sport', while a non-Aboriginal participant [WD] said, 'I liked the social aspects of school like playing footy and being with my mates'.

For many, the complexity in their lives combined with their neurodevelopmental challenges meant that they were unable to complete their schooling. One Aboriginal participant [NI] said, 'I didn't attend school for years'. They went on to say, 'I am trying to do a course [high school] while I am here [at Banksia]'. Another Aboriginal participant [FASD] said, 'I went to primary school sometimes but not high school. I didn't mind school, but I don't go to school no more'.

A few participants said that they did not like school. One non-Aboriginal participant [WD] said, 'I didn't like school. I was told I was stupid regularly'. Another non-Aboriginal participant [WD] said, 'I was in trouble all the time'. After describing multiple suspensions, he said, 'Miss, I hated school' and then shrugged and said, 'anyway, school gave up on me'.

Although most participants were between 13 and 15 years of age and still in the early stages of high school, many described irregular attendance and disengagement. One non-Aboriginal participant [WD] said, 'I done ok in school. I liked school but I'm not going back'. When asked why, they said, 'I didn't like the teachers much and I hated having to wear a uniform. I also hate it when they say one thing and then do another. It does my head in when things change'. Another Aboriginal participant [NI] said, 'it's not worth going back to school; I will just fail'. Other reasons given for irregular attendance or school disengagement included multiple school changes linked to multiple foster placements.

A few participants were interested in returning to school on their release from Banksia. One Aboriginal participant [WD] from a remote community was keen to return to school if it was different from what they had previously experienced. They described an alternative 'bush school':

Learning in a classroom first for reading and writing maybe, and the rest of the day learning how to survive-like our own first aid-how to eat, ya know, hunting and how to heal like, traditional medicines like. Then the kids might stay in school.

\section{Discussion}

\section{Locating Recovery Capital}

While most previous health and justice research have focused on the problems of young people, this research captured how young people in detention yarned about what makes them happy, what they hope for, their families and relationships, and their views about their education and school. Theirs were not only stories of the challenges of their circumstances, but also of their dreams for the future, their networks and their opportunities. The findings highlight the importance of family as a source of support and connection for participants. It was evident that being at home with family, having family members visit and the hope provided by the participants own children were all centrally important to participants' happiness.

However, the findings also suggest that some families are a source of negative recovery capital (Cloud and Granfield 2009), as evidenced by the participants' discussions about AOD use and the incarceration of family members. The participant who used AOD with their family because 'they 
all do it', and the participant who casually pointed to the adult prison as the location of their male relatives and their future, evidence the normalisation of family incarcerations for the Aboriginal participants. Both realities reflect the well-documented shift away from traditional norms and values held by pre-colonial Indigenous cultures (Kelley et al. 2017) and the subsequent trauma (Memmott et al. 2001; Rynne and Cassematis 2015).

Stability was a problem, particularly for those in the care of the state. Instability affects the capacity of individuals to build a sense of identity and connectedness. The participant who 'grew himself up' highlighted the vulnerability of the family and community structures and the influence that colonising forces have had on families and communities (Memmott et al. 2001). Nevertheless, there was an Aboriginal participant who recognised the potential for combining Western and traditional models in 'bush schools' to keep children and young people engaged with and attending school. These aspects of cultural capital held by the Aboriginal participants, positive or negative, can be supported by increasing social capital and positive social connections (Bougie and Senecal 2010; White and Cloud 2008) through positive peer support and role modelling (Nash, Hennessy and Collier 2019). This will be important for supporting these youth to shape their pathways to recovery.

The participants yarned about their education as a source of social and sporting opportunities for some and learning for others. Some participants liked school and said they did well. Some participants had attended multiple schools. Some spoke of being told they were 'stupid' and continually getting into trouble. Negative labelling fuels barriers to rehabilitation and should be challenged and rejected at a systemic level as part of establishing sustainable, recovery-oriented systems of change (Dingle et al. 2014). Many participants had ceased attendance or felt that schools had 'given up' on them. Assessing what activities may better suit these young people to increase positive community participation could better inform their recovery needs (Hennessy 2017). For children, schools are the place where peer relationships are built, and opportunities and resources are made available to pursue their goals. The findings show a clear need for services that help cultivate a strong culture and identity, and regular opportunities to participate in prosocial and cultural activities (Hovane, Dalton and Smith 2014).

The findings suggest that participants were not unmotivated in terms of their hopes for productive futures. While a few of the participants saw little in their futures, they still had hopes to be with family or stay out of prison. Many participants had job and study aspirations. Given the neurodevelopmental and other complex difficulties of the participants, the careers they identified such as bricklaying, working on a station, or working for ranger programs were not beyond their capacity with the right assistance and support. Significantly, participants did not yarn about relationships with teachers, officers or social support workers. While some participants saw their incarceration as an opportunity for education and futures (Laudet, Morgen and White 2006), there was little evidence of key professional relationships as sources of hope and inspiration. The absence of these relationships suggests that there is a need to consider applying relational, strength-based lenses (Slade 2010; Burford, Braithwaite and Braithwaite 2019) to policies which govern justice-involved youth, which factor in the effects of neurodevelopmental impairments and other complex difficulties that affect relationship building. By doing so, it would be possible to develop appropriate interventions, treatments and service responses based on trust and reciprocity (Putnam 2000).

\section{A 'Justice' Lens for Youth with Neurodevelopmental Disability and FASD}

The high prevalence of neurodevelopmental impairments and FASD diagnoses among the participants in this study alerts us to the widespread experience of impairments in this population (Baldry et al. 2015; Dias et al. 2013; Indig et al. 2011; Bower et al. 2018). The prevalence study results (Bower et al. 2018) should encourage a shift in the expectations of young people in the justice system and recognition of the effect of neurodevelopmental impairments on 
the behaviour of detained young people. Further, it provides an opportunity to support young people in developing strategies to deal with their neurodevelopmental disability and to find different pathways into the future. The relationships that the young people have within their families and networks; their participation in education, employment and prosocial activity for their futures; and their neurodevelopmental strengths and difficulties will all need consideration (Fast and Conry 2004; Bower et al. 2018; McLachlan et al. 2014; Snow, Bagley and White 2017; Kippin et al. 2018).

Youth with neurodevelopmental disabilities can have a range of impairments that result in impulsivity, poor attention, impaired memory and poor communication, and these youth are likely to be disadvantaged at all junctions of the criminal justice process. Their lack of (or different) understandings of social norms and inability to learn from experience exacerbate their involvement in crime (Blagg, Tulich and Bush 2015; Streissguth and O'Malley 2000), as do mental health problems, AOD problems and trauma (Hafekost et al. 2017; Indig, Frewen and Moore 2016).

Given the increased likelihood that these youth will come into contact with the law, there is a necessity to scaffold support for justice-involved youth differently. Whether young people in contact with the criminal justice system are fit to stand trial, have an ability to understand investigative procedures such as police interviews, can remember and retell their story accurately and can understand more broadly what may be required of them in court or detention is vitally important (Fast and Conry 2004; Streissguth and O'Malley 2000). Equally important is that they have their neurodevelopmental challenges considered in their rehabilitative efforts and the planning of their futures. Understanding their recovery capital assets in the justice context, including their neurodevelopmental resources that may help or hinder this process is imperative to achieving a PYJ (Butts, Bazemore and Meroe 2010).

The findings from this qualitative study suggest that it is possible to assess recovery capital assets in this population and to utilise those assets as part of a therapeutic process using neurodevelopmental diagnostic information. However, further research is required to confirm the salient dimensions of recovery capital in the context of justice. Table 1 provides a broad conceptualisation of the qualitative data connections with positive and negative justice capital. There is potential for developing an assessment model that measures recovery capital in the justice context and facilitates knowledge about neurodevelopmental disability, disadvantage, trauma and the recovery needs of justice-involved youth. This could also assist in establishing whether applying recovery-focused assessment models as a routine aspect of youth justice service provision can assist in reducing the rising imprisonment rates of Indigenous youth in Australia. 
Table 1: Positive and Negative Justice Capital: Data Connections

\begin{tabular}{|c|c|c|}
\hline Data connections & Negative justice capital & Positive justice capital \\
\hline $\begin{array}{l}\text { Neurodevelopmental } \\
\text { Disability }\end{array}$ & $\begin{array}{l}\text { Undiagnosed neurodevelopmental disability } \\
\text { FASD, } \\
\text { Neurodevelopmental impairments } \\
\text { No access to legal advocacy services } \\
\text { Unrecognised language need } \\
\text { No interpreters } \\
\text { Lack of opportunity engagement with } \\
\text { community activities or organisations } \\
\text { Social exclusion from community and its } \\
\text { assets }\end{array}$ & $\begin{array}{l}\text { Access to Strength base, holistic } \\
\text { diagnostic assessments } \\
\text { Disability services and support } \\
\text { Access to special education support } \\
\text { Legal representation and advocacy } \\
\text { Speaking multiple languages } \\
\text { Interpreter services } \\
\text { Plain language explanations } \\
\text { Destigmatising narrative/optimistic } \\
\text { language } \\
\text { Hope and future aspirations } \\
\text { Goal setting and skill development } \\
\text { Engagement with community (sport and } \\
\text { employment) }\end{array}$ \\
\hline AOD Use & $\begin{array}{l}\text { Untreated problematic AOD use } \\
\text { Negative peer influences }\end{array}$ & $\begin{array}{l}\text { Access to rehabilitation } \\
\text { Positive peer support and mentoring }\end{array}$ \\
\hline Trauma and past harm & $\begin{array}{l}\text { Negative family influences } \\
\text { Social isolation } \\
\text { Intergenerational trauma } \\
\text { Culture denied } \\
\text { Disconnection from country } \\
\text { Fractured cultural identity }\end{array}$ & $\begin{array}{l}\text { Family relationships supported through } \\
\text { contact visits } \\
\text { Strong relationships with family } \\
\text { Safe housing } \\
\text { Relationships based on trust and mutual } \\
\text { obligation } \\
\text { Peer support and positive mentoring } \\
\text { Recovery and healing services } \\
\text { Commitment to culture, community and } \\
\text { country } \\
\text { Opportunity for cultural activity } \\
\text { Strong Cultural identity }\end{array}$ \\
\hline
\end{tabular}

\section{Conclusion}

Justice-involved youth are well understood to be a traumatised population with high levels of neurodevelopmental disability. The examination of recovery initiatives is consistent with a move towards PYJ for justice-involved youth, regardless of cultural identity. The views presented in this article of young people in detention provide the opportunity for an improved understanding of recovery capital in the justice context and to consider strength-based, future-focused assessment models for recovery. Most of the young people described backgrounds of adversity, with threequarters of the participants identifying as Aboriginal and therefore likely to be carrying additional intergenerational trauma. As such, the application of a recovery-focused model of assessment that explores the personal, social and community capital assets possessed by justice-involved youth provides a way to understand and respond to their neurodevelopmental needs, build on their skills and assist them to plan pathways to achieve their goals. A complete appreciation of the challenges and support needs of these young people requires the specific consideration of recovery capital in the justice context and, as such, we advocate developing a broad assessment tool that measures the positive and negative recovery capital assets of justice-involved youth. 


\section{Acknowledgments}

The authors thank the young people who participated in the study for sharing their stories. We thank all at Banksia Hill Detention Centre. We thank the study team, the members of the Consumer and Community Reference Group, the Steering Group and the Reference Group, and the Chief Investigators and Associate Investigators. Sharynne Hamilton thanks the Elder Coresearchers with the Ngulluk Koolunga Ngulluk Koort (Our Children, Our Heart) Project, Telethon Kids Institute for sharing their knowledge and wisdom and for their contribution to the interpretation of the data from this research.

This research is funded by the National Health and Medical Research Council (\# APP1072072) and supported by the NHMRC Reducing the Effects of Antenatal Alcohol on Child Health Centre of Research Excellence (\#1110341). SLH is supported by an Australian Government Research Training Program Scholarship, the Peter and Ann Hector Award, the FASD Research Australia Centre of Research Excellence, and the Centre of Research Excellence Indigenous Health and Alcohol, University of Sydney (NHMRC \#APP1117198).

Disclaimer: Any material published or made publicly available by the authors cannot be considered as either endorsed by the Department of Justice or an expression of the policies or the views of the Department. Any errors of omission or commission are the responsibility of the researchers.

Correspondence: Sharynne Hamilton, PhD Candidate, Telethon Kids Institute, Hospital Ave, Nedlands WA 6001. Email: sharynne.hamilton@telethonkids.org.au

\section{References}

Attride-Stirling J (2001) Thematic networks: An analytic tool for qualitative research. Qualitative Research 1(3): 385-405. https://doi.org/10.1177/146879410100100307

Australian Bureau of Statistics (2017) 4517.0 Prisoners in Australia, 2017. Released 6 December 2018. Available at https://www.abs.gov.au/ausstats/abs@.nsf/Lookup/by\%20Subject/4517.0 2018 Media\%20Releas e $\sim$ Prisoner\%20numbers\%20up\%204\%20per\%20cent\%20from $\% 202017 \% 20$ (Media\%20Release) 100 (accessed 9 December 2019).

Australian Institute of Health and Welfare (2018) Youth Detention Population in Australia 2018 Available at https://www.aihw.gov.au/reports/youth-justice/youth-detention-population-in-australia2018/contents/table-of-contents (accessed 9 December 2019).

Baldry E, McCausland R, Dowse L and McEntyre E (2015) A Predictable and Preventable Path: Aboriginal People with Mental and Cognitive Disabilities in the Criminal Justice System. Available at https://www.mhdcd.unsw.edu.au/ (accessed 9 December 2019).

Bennett T and Holloway K (2009) The causal connection between drug misuse and crime. British Journal of Criminology 49(4): 513-531. https://doi.org/10.1093/bjc/azp014

Bessarab D and Ng'andu B (2010) Yarning about yarning as a legitimate method in Indigenous research. International Journal of Critical Indigenous Studies 3(1): 37-50. https://doi.org/10.5204/ijcis.v3i1.57

Best D and Laudet A (2010) The Potential of Recovery Capital. London: RSA.

Best D (2014) Strength, Support, Setbacks and Solutions: The developmental pathway to addiction recovery. Brighton: Pavilion Publishing.

Best D and Savic M (2015) Substance abuse and offending: pathways to recovery. In Sheehan R and Ogloff J (eds) Working within the Forensic Paradigm: Cross-Discipline Approaches for Policy and Practice: 259271. Abingdon, Oxon: Routledge.

Best D, Beckwith M, Haslam C, Haslam A, Jetten J, Mawson E and Lubman D (2016) Overcoming alcohol and other drug addiction as a process of social identity transition: The Social Identity Model of 
Recovery (SIMOR). Addiction Research and Theory 24 (2): 111-123

https://doi.org/10.3109/16066359.2015.1075980

Best D (2019) Pathways to recovery and desistance: The role of the social contagion of hope. Bristol: Policy Press.

Blagg H (2008) Crime, Aboriginality and the Decolonisation of Justice. Sydney: Federation Press.

Blagg H, Tulich T and Bush Z (2015) Diversionary pathways for Indigenous youth with FASD in Western Australia: Decolonising alternatives. Alternative Law Journal 40(4): 257-260. https://doi.org/10.1177/1037969X1504000409

Bower C, Watkins R, Mutch R, Marriott R, Freeman J, Kippin N, Safe B et al. (2018) Fetal alcohol spectrum disorder and youth justice: a prevalence study among young people sentenced to detention in Western Australia. BMJ Open 8 e019605. http://dx.doi.org/10.1136/bmjopen-2017-019605

Bougie E and Senecal S (2010) Registered Indian children's school success and intergenerational effects of residential schooling in Canada. The International Indigenous Policy Journal 1(1): 1-41. https://doi.org/10.18584/iipj.2010.1.1.5

Bourdieu P (1985) The forms of capital. In Richardson JG (ed.) Handbook of Theory and Research for the Sociology of Education: 241-258. New York: Greenwood.

Brunelle N, Cousineau M and Brochu S (2005) Juvenile drug use and delinquency: Youths' accounts of their trajectories. Substance Use \& Misuse 40(5): 721-734. https://doi.org/10.1081/JA-200055404t

Burford G, Braithwaite J and Braithwaite V (eds) (2019) Restorative and Responsive Human Services. New York: Routledge.

Butts J, Bazemore G and Meroe AS (2010) Positive Youth Justice: Framing Justice Interventions Using the Concepts of Positive Youth Development. Washington: Coalition for Juvenile Justice.

Caudy M, Tillyer M and Tillyer R (2018) Jail versus probation: A gender-specific test of differential effectiveness and moderators of sanction effects. Criminal Justice \& Behavior 45(7): 949-968. https://doi.org/10.1177/0093854818766375

Cavadino M and Dignan J (2006) Penal Systems: A Comparative Approach. Thousand Oaks and New Delhi: Sage Publications.

Clark CD (2011) In a Younger Voice: Doing Child-Centered Qualitative Research. New York: Oxford University Press.

Cloud W and Granfield R (2009) Conceptualizing recovery capital: Expansion of a theoretical construct. Substance Use and Misuse 43(12-13): 1971-1986. https://doi.org/10.1080/10826080802289762

Coyhis D and White W (2006) Alcohol Problems in Native America: The Untold Story of Resistance and Recovery-The Truth about the Lie. Colorado Springs: White Bison, Inc.

Cunneen C and Rowe S (2014) Changing narratives: Colonised people, criminology and social work. International Journal for Crime, Justice and Social Democracy 3(1): 49-67. https://doi.org/10.5204/ijcjsd.v3i1.138

De Maio JA, Zubrick SR, Silburn SR, Lawrence DM, Mitrou FG, Dalby RB, Blair EM, Griffin J, Milroy H and Cox A (2005) The Western Australian Aboriginal Child Health Survey: Measuring the Social and Emotional Wellbeing of Aboriginal Children and Intergenerational Effects of Forced Separation. Available at https://www.telethonkids.org.au/globalassets/media/documents/aboriginalhealth/measuring_social_and_emotional_wellbeing.pdf (accessed 9 December 2019).

Dias S, Ware RS, Kinner SA and Lennox NG (2013) Co-occurring mental disorder and intellectual disability in a large sample of Australian prisoners. Australian \& New Zealand Journal of Psychiatry 47(10): 938944. https://doi.org/10.1177\%2F0004867413492220

Dingle GA, Stark C, Cruwys T and Best D (2014) Breaking good: Breaking ties with social groups may be good for recovery from substance misuse. British Journal of Social Psychology 54(2): 236-254. https://doi.org/10.1111/bjso.12081

Dunkel F (2014) Juvenile justice systems in Europe-Reform developments between justice, welfare and 'new punitiveness'. Criminological Studies 1: 31-76. Available at http://eigep.eu/wpcontent/uploads/2018/01/Dunkel2014 juvenile justice Europe.pdf (accessed 17 August 2019).

Durkheim E (1984) The Division of Labor in Society. New York: Free Press.

Farrington DP (2007) Childhood risk factors and risk-focused prevention. In Maguire M, Morgan R and Reiner R (eds) The Oxford Handbook of Criminology: 602-640. Oxford: Oxford University Press.

Fast D and Conry J (2004) The challenge of fetal alcohol syndrome in the criminal legal system. Addiction Biology 9(2): 161-166. https://doi.org/10.1080/13556210410001717042

Fredericks B, Adams K, Finlay S, Fletcher G, Andy S, Briggs L, Briggs L and Hall R (2011) Engaging the practice of yarning in Action Research. Action Learning and Action Research Journal 17(2): 7-19. Available at 
https://eprints.qut.edu.au/48053/1/Engaing_yarning_in Action Research\%2C ALAR Journal.pdf (accessed 14 July 2019).

Freeman J, Condon C, Hamilton S, Mutch R, Bower C and Watkins R (2018) Challenges in Accurately Assessing Prenatal Alcohol Exposure in a Study of Fetal Alcohol Spectrum Disorder in a Youth Detention Center. Alcohol Clinical Experimental Research 43(2): 309-316.

https://doi.org/10.1111/acer.13926

Goddard T and Myers R (2017) Against evidence-based oppression: Marginalized youth and the politics of risk-based assessment and intervention. Theoretical Criminology 21(2): 151-167. https://doi.org/10.1177\%2F1362480616645172

Goldson B and Muncie J (2012) Towards a global 'child friendly' juvenile justice? International Journal of Law, Crime and Justice 40(1): 47-64. https://doi.org/10.1016/j.ijlcj.2011.09.004

Granfield R and Cloud W (2001) Social context and 'natural recovery': The role of social capital in the resolution of drug-associated problems. Substance Use and Misuse 36: 1543-70. https://doi.org/10.1081/JA-100106963

Hafekost K, Lawrence D, O'Leary C, Bower C, Semmens J and Zubrick SR (2017) Maternal alcohol use disorder and risk of child contact with the justice system in Western Australia: A population cohort record linkage study. Alcoholism: Clinical and Experimental Research 41(8): 1452-1460. https://doi.org/10.1111/acer.13426

Hamilton S, Reibel T, Watkins R, Mutch R, Kippin N, Freeman J, Passmore H et al. (2019a). "He has problems; he is not the problem ..." A qualitative study of noncustodial staff providing services for young offenders assessed for Foetal Alcohol Spectrum Disorder in an Australian youth detention centre. Youth Justice 19(2): 137-157. https://doi.org/10.1177/1473225419869839

Hamilton S, Reibel T, Maslen S, Watkins R, Freeman J, Passmore H, Mutch R et al. (2019b). Disability “injustice": The benefits and challenges of "yarning" with young people undergoing diagnostic assessment for Fetal Alcohol Spectrum Disorder in a youth detention centre. Qualitative Health Research 30(2): 314-327. https://doi.org/10.1177/1049732319882910

Harmes M, Hopkins S and Farley H (2019) Beyond incarcerated identities: Identity, bias and barriers to higher education in Australian prisons. International Journal of Bias, Identity and Diversities in Education 4(1): 211-234. https://doi.org/10.4018/IJBIDE.20190101

Haslam SA, Reicher SD and Levine M (2012) When other people are heaven, when other people are hell: How social identity determines the nature and impact of social support. In Jetten J, Haslam C and Haslam SA (eds) The Social Cure: Identity, Health and Well-Being. 157-174. New York, NY: Psychology Press.

Hennessy EA (2017) Recovery capital: a systematic review of the literature. Addiction Research \& Theory 25(5): 349-360. https://doi.org/10.1080/16066359.2017.1297990

Hovane V, Dalton T and Smith P (2014) Aboriginal rehabilitation programs. In Dudgeon P, Milroy H and Walker R (eds) Working Together: Aboriginal and Torres Strait Islander Mental Health and Wellbeing Principles and Practice 2nd edn: 509-522. Canberra: Australian Government Department of the Prime Minister and Cabinet.

Indig D, Frewen A and Moore E (2016) Predictors and correlates of re-incarceration among Australian young people in custody. Australian and New Zealand Journal of Criminology 49(1): 73-89. https://doi.org/10.1177\%2F0004865814550534

Indig D, Vecchiato C, Haysom L, Beilby R, Carter J, Champion U, Gaskin C, Heller E, Kumar S, Mamone N, Muir P, van den Dolder P and Whitton G (2011) 2009 NSW Young People in Custody Health Survey: Full Report. Sydney: Justice Health and Juvenile Justice.

Jetten J, Haslam C, Haslam SA, Dingle G and Jones JM (2014) How groups affect our health and well-being: The path from theory to policy. Social Issues and Policy Review 8(1): 103-130. https://doi.org/10.1111/sipr.12003

Kaspar V (2014) The lifetime effect of residential school attendance on Indigenous health status. American Journal of Public Health 104(11): 2184-2190. https://doi.org/10.2105/AJPH.2013.301479

Kelley A, Bingham D, Brown E and Pepion L (2017) Assessing the impact of American Indian peer recovery support on substance use and health. Journal of Groups in Addiction \& Recovery 12(4): 296308. https://doi.org/10.1080/1556035X.2017.1337531

Kippin N, Leitãoa S, Watkins R, Finlay-Jones A, Condon C, Marriott R, Mutch R et al. (2018) Language diversity, language disorder, and fetal alcohol spectrum disorder among youth sentenced to detention in Western Australia. International Journal of Law and Psychiatry 61: 40-49.

https://doi.org/10.1016/i.i.jp.2018.09.004 
Lambert V and Glacken M (2011) Engaging with children in research: Theoretical and practical implications of negotiating informed consent/assent. Nursing Ethics 18(6): 781-801.

https://doi.org/10.1177\%2F0969733011401122

Laudet A, Morgen K and White W (2006) The role of social supports, spirituality, religiousness, life meaning and affiliation with 12-step fellowships in quality of life satisfaction among individuals in recovery from alcohol and drug use. Alcoholism Treatment Quarterly 24(102): 33-73. https://doi.org/10.1300/J020v24n01 04

MacDonald C and Steenbeek A (2015) The Impact of colonization and Western assimilation on health and wellbeing of Canadian Aboriginal people. International Journal of Regional and Local History 10(1): 32-46. https://doi.org/10.1179/2051453015Z.00000000023

Martin K (2008) Please Knock Before You Enter: Aboriginal Regulation of Outsiders and the Implications for Researchers. Brisbane: Post Pressed.

McLachlan K, Roesch R, Viljoen J and Douglas K (2014) Evaluating the psycholegal abilities of young offenders with fetal alcohol spectrum disorder. Law and Human Behavior 38: 10-22. Available at https://psycnet.apa.org/doi/10.1037/lhb0000037 (accessed 4 August 2019).

McNeill F and Maruna S (2007) Giving up and giving back: Desistance, generativity and social work with offenders. In McIvor G and Raynor P (eds) Developments in Social Work with Offenders (Research Highlights in Social Work 48):224-339. London: Jessica Kingsley.

McNeill F and Whyte B (2007) Reducing Reoffending: Social Work and Community Justice in Scotland. Cullompton, England: Willan.

Memmott P, Stacy R, Chambers C and Keys C (2001) Violence in Aboriginal Communities. Canberra: Attorney-General's Department.

Morris A and Giller H (1983) Providing Criminal Justice for Children. London: Hodder Arnold.

Nash AJ, Hennessy EA and Collier C (2019) Exploring recovery capital among adolescents in an alternative peer group. Drug and Alcohol Dependence 199: 136-143.

https://doi.org/10.1016/i.drugalcdep.2019.02.025

NVivo Pro Qualitative Data Analysis Software 2016, Version 11, software, QSR International Pty Ltd, Melbourne.

Office of the Inspector of Custodial Services (2018) Report of an Announced Inspection of Banksia Hill Juvenile Detention Centre. Perth: Office of the Inspector of Custodial Services.

Passmore H, Giglia R, Watkins R, Mutch R, Marriott R, Pestell C, Zubrick S et al. (2016) Study protocol for screening and diagnosis of fetal alcohol spectrum disorders (FASD) among young people sentenced to detention in Western Australia. BMJ Open 6(6): e012184. https//doi.org/10.1136/bmjopen-2016012184

Passmore H, Mutch R, Burns S, Watkins R, Carapetis J, Hall G and Bower C. (2018) Fetal Alcohol Spectrum Disorder (FASD): Knowledge, attitudes, experiences and practices of the Western Australian youth custodial workforce. International Journal of Law and Psychiatry 59: 44-52. https://doi.org/10.1016/j.ijlp.2018.05.008

Putnam RD (2000) Bowling Alone: The Collapse and Revival of American Community. London: Simon \& Schuster.

Reitano J (2017) Adult Correctional Statistics in Canada 2015/2016. Available at http://www.statcan.gc.ca/pub/85-002-x/2017001/article/14700-eng.htm (accessed 14 July 2019).

Roach K and Bailey A (2009) The relevance of fetal alcohol spectrum disorder and the criminal law from investigation to sentencing. University of British Columbia Law Review 42: 1-68. Available at https://ssrn.com/abstract=1616843 (accessed 20 May 2019).

Rynne J and Cassematis P (2015) Assessing the prison experience for Australian First Peoples: A prospective research approach. International Journal for Crime, Justice and Social Democracy 4(1): 96112. https://doi.org/10.5204/ijcjsd.v4i1.208

Scott D and Gosling H (2016) Before prison, instead of prison, better than prison: Therapeutic communities as an abolitionist real utopia. International Journal for Crime, Justice and Social Democracy 5(1): 52-66. https://doi.org/10.5204/ijcjsd.v5i1.282

Slade M (2010) Mental illness and well-being: The central importance of positive psychology and recovery approaches. BMC Health Services Research 10(1): https://doi.org/10.1186/1472-6963-10-26

Smith J, Flower P and Larkin M (2009) Interpretative Phenomenological Analysis: Theory, Method and Research. Qualitative Research in Psychology 6(4): 346-347. https://doi.org/10.1080/14780880903340091 
Snow P, Bagley K and White D (2017) Speech-language pathology intervention in a youth justice setting: Benefits perceived by staff extend beyond communication. International Journal of Speech-Language Pathology 20(4): 458-467. https://doi.org/10.1080/17549507.2017.1297484

Streissguth AP and O'Malley K (2000) Neuropsychiatric implications and long-term consequences of fetal alcohol spectrum disorders. Semin Clin Neuropsychiatry 5(3): 177-190. https://doi.org/10.1053/scnp.2000.6729

Ulmer J and Bradley M (2018) Punishment in Indian country: Ironies of federal punishment of Native Americans. Justice Quarterly 35(5): 751-81. https://doi.org/10.1080/07418825.2017.1341540

Ward T and Maruna S (2007) Rehabilitation: Beyond the Risk Paradigm. London: Routledge.

Weatherburn D and Ramsey S (2016) What's Causing the Growth in Indigenous Imprisonment in NSW? Sydney: NSW Bureau of Crime Statistics and Research. Available at https://www.bocsar.nsw.gov.au/Documents/BB/Report-2016What\%27s-causing-the-growth-inIndigenous-Imprisonment-in-NSW-BB118.pdf (accessed 17 June 2019).

White W and Cloud A (2008) Recovery capital: A primer for addictions professionals. Counselor 9(5): 22-27. Available at http://www.williamwhitepapers.com/pr/2008RecoveryCapitalPrimer.pdf (accessed 17 January 2019).

Winterdyck J (2014) Juvenile Justice: International Perspectives, Models and Trends. Boca Raton: CRC Press.

Please cite this article as:

Hamilton, S L, Maslen S, Best D, Freeman J, O’Donnell M, Reibel T, Mutch R C and Watkins R (2020) Putting 'justice' in recovery capital: Yarning about hopes and futures with young people in detention. International Journal for Crime, Justice and Social Democracy 9(2): 20-36. https://doi.org/10.5204/ijcjsd.v9i2.1256 